\title{
Biological Control of Sheath Blight Disease of Rice by using Antagonistic Bacteria
}

\author{
M. A. Bashar ${ }^{a}$, M. A. Hossain ${ }^{b}$, M. M. Rahman ${ }^{a}$, M. N. Uddin' ${ }^{c}$ and M. N. Begum \\ ${ }^{a}$ University of Dhaka, ${ }^{b}$ Bangladesh Rice Research Institute, Gazipur and ${ }^{c} P \& D$, Bangladesh Council of \\ Scientific and Industrial Research (BCSIR), Dhaka, Bangladesh
}

\begin{abstract}
The study was made to detect and identify antagonistic bacteria to control Rhizoctonia solani, a causal organism of sheath blight (ShB) disease of rice. Isolation of antagonistic bacteria was done from ShB infected rice leaf collected from the districts of Gazipur, Rajshahi, Bogra and Comilla. Fifty isolates of bacteria were isolated. These isolates were tested for antagonism against ShB pathogen of in PDA medium. Among the isolates of antagonistic bacteria (both fluorescent and non fluorescent), eleven produced more than $15 \mathrm{~mm}$ inhibition zone, were selected for this study. Remarkable inhibition zone producing ten isolates were selected to observe their antagonistic behaviour by soaking the sclerotia of Rhizoctonia solani and rice seedlings in different hours into bacterial suspension of $3.84 \times 10^{7} \mathrm{CFU} / \mathrm{ml}$. Both the in vitro and in vivo rom showed that the sclerotial germination and sheath blight symptom expression were delayed 6-9 days. Soaking of both seedlings and sclerotia with the test bacteria was found most effective to control ShB (38\% - 100\%) than soaking of seedlings alone with bacterial suspension at different hours. However, BanShbFPS5 (2)B, BanShb738(3), BanShb738(2) and BanShb581(1), the four antagonistic bacterial isolates could be applied as biological agent to control sheath blight disease of rice and they could control sheath blight disease development and could delay the epidemics of the disease.
\end{abstract}

Key words: Biological control, Sheath blight disease, Rhizoctonia solani, Antagonistic bacteria

\section{Introduction}

Rice is the staple food for about 140 million people of Bangladesh. It provides about $75 \%$ of the total calories and $55 \%$ of the total protein in a typical diet in Bangladesh (BBS, 2004).

Low yield of rice is attributed to various factors. Among them, vulnerability of crop to pests and diseases is important one. Rice diseases are caused by different groups of pathogenic microorganisms. Thirty six fungal, twenty one viral, six bacterial and six nematode diseases have been recorded in rice (Ou, 1985). In Bangladesh, 31 rice diseases have been so far identified of which ten are considered as major (Miah and Shahjahan, 1987 and Anon, 1995). The sheath blight (ShB) disease of rice caused by Rhizoctonia solani is prevalent in almost all rice-growing countries of the world. Both local and high yielding varieties are susceptible to this disease (Naidu, 1989). The pathogen attacks the rice plant at maximum tillering stage by sclerotium, the primary source of inoculum that over winter in soil and plant debries $(\mathrm{Ou}$,
1985). Sheath blight of rice causes poor filling of the grains and emergence of panicles. It may cause about 25-32\% yield loss in rice in Bangladesh (Shahjahan et al., 1986).

Sheath blight has becoming as an increasing problem for rice cultivation in Bangladesh. High temperature and relative humidity during crop growth favour development of sheath blight disease, short strature, high tillering and high nitrogen responsive varieties are comparatively more susceptible as the micro climates inside the rice canopy is more favourable than those of the traditional ones of tall plant type with low tillering ability (Miah et al., 1985).

Biological control is the most accepted, eco-friendly method to control any type of the pest and disease because this method has not any negative impact on the environment. There are few reports available regarding biocontrol of sheath blight disease of rice (Hossain et al., 2001). The fluorescent and non-fluorescent strains of a number of antagonistic bacteria associated with upland and lowland rice rhizos-

\footnotetext{
* Corresponding author: E-mail:
} 
phere soils have been found effective in laboratory, green house and also in the field against $R$. solani (Islam et al., 2003). Objectives of the study are isolation and identification of antagonistic bacteria and $R$. solani from sheath blight infected plants and to screen of antagonistic bacteria to control sheath blight disease in laboratory and field.

\section{Materials and Methods}

\section{Isolation of $\boldsymbol{R}$. solani from sheath blight infected plants}

Sheath blight infected rice plants were collected from some selected rice fields of BRRI, Gazipur. Infected culms were cut off with a pair of sterilized scissors, kept in a sterilized polyethylene bag and brought in to the laboratory for microscopic study and isolation work. The fungus was isolated from infected parts of the rice plants following Tissue planting and Blotter methods.

\section{Tissue plating method}

Sheath blight infected sheath with culm was collected and cut into small pieces (5-6 mm) with the help of sterilized scissors. The cut pieces were washed with sterile water for 2 minutes and then surface sterilized by 5\% Clorox for 2 minutes. Finally, these pieces of leaves were washed with sterile water for 2-3 minutes and were dried on sterile tissue paper. The dried samples were placed potato dextrose agar (PDA) plate and incubated for 7 days at room temperature (25 \pm $2^{\circ} \mathrm{C}$ ). Fungus was identified based on mycelial growth, colony character, sclerotia formation and sclerotial size (Akter et al., 2003).

\section{Blotter method}

In this method, moist chamber was made by placing two layers of blotting paper on the bottom of a $9 \mathrm{~cm}$ diameter petriplate. The moist chambers were sterilized in an autoclave at $120^{\circ} \mathrm{C}$ under $1 \mathrm{~kg}$ pressure for 15 minutes. A total of 50 inocula were transferred in 13 moist chambers. Each of the moist chambers contained 4 inocula except one which contained only two inocula. The inoculated moist petriplates were incubated at room temperature $\left(25 \pm 2^{\circ} \mathrm{C}\right)$ for 7 days.

\section{Pathogenicity test of $R$. solani isolates}

Pathogenicity tests were performed in the green house at BRRI, Joydebpur, Gazipur. More than fifteen sprouted seeds of a highly ShB susceptible variety, BR11 were sown in each earthen pot (8"x10"). Finally, three plants were kept in each pot. Fifty-day-old plants were used for inoculation. Then five sclerotia were placed in between the base of the two tillers for each hill. Those isolates produced typical ShB symptom were selected and reisolated from the infected plants. Sclerotia of uniform size were aseptically harvested from seven-day-old cultures of $R$. solani grown on PDA medium and were preserved in test tubes at $4^{\circ} \mathrm{C}$.

\section{Isolation and preservation of bacteria}

Isolation of bacteria was done from sheath blight infected sheath sample collected from the districts of Rajshahi, Bogra, Comilla and Gazipur during T. Aman in 2002 and 2005. A total of 139 infected sheath samples was used to isolate bacteria. After surface sterilization, an infected sample with typical advancing lesion was selected. The leaf was cut into small pieces having $1 / 4$ th infected and 3/4th healthy tissues. A few pieces of such samples were soaked in $20 \mathrm{ml}$ sterilized distilled water in a small sterilized beaker for one hour. The sample was shaken with hand for few minutes and then the sample soaked water was placed into KBA medium $\left(\mathrm{K}_{2} \mathrm{HPO}_{4}\right.$ Dibasic-2.5g, $\mathrm{MgSO}_{4}-6 \mathrm{~g}$, Peptone-20g, Glycerol10g, Agar-20g, Distilled water $1000 \mathrm{ml}, \mathrm{pH}-7.2)$ the help of sterile loop. The most prevalent bacterial colonies in the plate were selected, especially florescent colonies. However, single colony for each isolate was selected, streaked and restreaked on to the peptone sucrose agar (PSA) medium to get the pure culture. The pure culture of the suspected antagonistic bacteria was grown in peptone sucrose agar slant at $25 \pm 2{ }^{\circ} \mathrm{C}$ for 48 hrs in an incubator. All the isolated antagonistic bacteria were marked with number and finally kept in sterile water at room temperature for further use.

\section{In vitro screening of sheath blight associated bacteria for antibiosis}

A total of 50 bacterial isolates were tested for antagonism against $R$. solani. Test isolate of $R$. solani was grown in PDA medium. Approximately $15 \mathrm{ml}$ of PDA medium was poured in each petriplate. The petriplate was used after 72 hours of plating. A small block (5 mm) of growing mycelia with medium was placed in the center of the petriplate. To see the antagonism, the ShB associated bacteria was placed on three places around the block (5 mm) of growing mycelia of $R$. solani on PDA medium. The inoculated petriplate with ShB associated bacteria was incubated at $25 \pm 2{ }^{\circ} \mathrm{C}$ for $24 \mathrm{hrs}$. All the strains were used in the initial screening for in vitro antibiosis against $R$. solani. The production of inhibition zone between the test bacterium and $R$. solani was the indication of antagonism. Finally, the isolates produced more 
than $15 \mathrm{~mm}$ inhibition zone were selected, marked and preserved in sterile water at room temperature for further use.

\section{In vitro effect of antagonistic bacterial isolates on the ger- mination of sclerotia of $R$. solani}

Fifty antagonistic bacteria were isolated, and among them only three isolates were considered here on the basis of maximum antibiosis. The bacterial isolates were BanShb581 (1), BanShbFPS5(2) and BanShb738(3). Sclerotia of R. solani were soaked in bacterial suspension for 1, 3, 6 and 12 hours (overnight) to see the antagonistic effect. Two controls were used for this purpose. Sclerotia of $R$. solani treated with water and neither with water nor bacterial suspension served as control 1 and 2, respectively. Germination of treated sclerotia was determined in water agar. Twenty sclerotia were used for each bacteria. Five sclerotia were placed for each replication to observe its germination.

\section{In vivo effect of antagonistic bacterial isolates to control sheath blight in rice}

A total of 96 pots were prepared and filled with air dried soil. A highly ShB susceptible cultivar, BR11 (Mukta) was selected for this study. Seeds of BR11 were sown in the cemented tray in BRRI green house. Ten-day old seedlings were transplanted in pots using single seedling. Three seedlings were planted in each pot. Three selected antagonistic bacterial isolates namely; BanShb581 (S1), BanShbFPS5 (S2) and BanShb738(S3) were revived from sterile water similarly as stated in the previous experiment. The harvesting of $R$. solani sclerotia was done following the method mentioned elsewhere. The sclerotia were soaked for $1 \mathrm{hr}, 3 \mathrm{hr}, 6 \mathrm{hr}$ and $12 \mathrm{hr}$ (or overnight) in the three different antagonistic bacterial suspension as mentioned earlier. The bacteria soaked 20 sclerotia for each bacteria were placed at the center of the seedling just above the water level by the sterile forcep. Plants were inoculated at maximum tillering stage. The inoculated seedlings with treated sclerotia were observed for ShB disease development. Disease initiation data were recorded accordingly to find the effect of bacteria. Sheath blight disease development was recorded with the dates of disease initiation and disease incidence. Per cent tiller infection (\%TI) and per cent relative lesion height (\% RLH) were also recorded at maximum tillering, booting and milky stages.
Effect of isolates of antagonistic bacteria to control sheath blight disease in rice

A high yielding cultivar BR11 (Mukta) was selected for this study. Clean, healthy and mature seeds were soaked in tap water for 24 hours and incubated for 48 hours for sprouting before sowing on the net of the tray. The sprouted seeds were placed in a line on the net covering which was guided by stylo-foam, so that the seedlings grew in line and each line had 40 sprouted seeds. Finally, 30 seedlings were kept and maintained for inoculation. Culture solution was prepared and poured in a plastic tray $(30 \times 20 \times 15 \mathrm{~cm})$ with a just submerged net covering. The culture solution was maintained a few $\mathrm{mm}$ above the net so that the sprouted seeds could not be merged under water. The same water level was maintained throughout the experimental period. Seven selected isolates of antagonistic bacteria namely BnShbFPS5 (2)B, BnShbFPS 6(1), BnShb581(1), BnShb738(3), BnShb725(1), BnShb650(1) and BnShb728(2) were revived from sterile water. The sclerotia were soaked over night in different antagonistic bacterial suspension. The bacteria soaked 20 sclerotia for each bacterial isolate were placed at the center of the seedling just above the water level by the sterile forcep. Fifteen-day old seedlings were used for inoculation. One antagonistic bacteria soaked sclerotia was used for each line of seedlings and 20 seedlings were used for testing each bacteria. The inoculated seedlings with treated sclerotia were observed for ShB disease development. Disease initiation data were recorded to see the effect of bacteria. Sheath blight disease development and disease incidence were recorded in the 1st, 2nd and 3rd weeks of inoculation. Data were recorded visually by observing the symptoms.

\section{Effect of seedlings soaked with an antagonistic bacteria to control sheath blight}

The experiment was conducted in the net house of Plant Pathology Division, BRRI, Gazipur, during June December, 2005. BanShb738(3) was used for soaking of sclerotia.

Effect of seedlings and sclerotia soaked with antagonistic bacteria to control sheath blight

A total of 44 pots were prepared and filled with air dried soil. The same variety, BR11 was used for this study. Seeds of BR11 were sown in the cemented tray in BRRI green house. Ten-day old seedlings were transplanted in pots. Before transplanting, the seedlings were soaked over night in bacte- 
rial suspension with a control (seedling soaking with water only / no bacterial suspension). Three seedlings were used in each pot. Ten antagonistic bacterial isolates, i.e, BanShbFPS.5(2)B, BanShbFPS6(1), BanShb581(1), BanShb725(1), BanShb650(1), BanShb728(2), BanShb806(3)A, BanShb805(3), BanShb726(4) and BanShb738(3) were revived and multiplied on PSA medium. Bacterial suspension was prepared as stated in the previous experiment. The harvesting of $R$. solani sclerotia was done following the method mentioned earlier. The sclerotia were soaked over night in different antagonistic bacterial suspensions. Fifteen-day old seedlings were used for inoculation purpose. The inocula were kept moist by sprinkling water for next three days. Sheath blight disease development and incidence were recorded 7, 14, 21 and 28 days after inoculation. Data was recorded visually by observing the symptoms. Completely Randomized Block Design (CRBD) was used for experiment undertaken. The collected data were analyzed statistically and the mean, standard deviation and other cal- culations are evaluated considering 5\% level of significance by a computer package programme called SPSS (Statistical Package for Social Science) of version 14, now frequently being used to analyze all sort of data and this version was developed by SPSS Inc. in 2006.

\section{Results and Discussion}

\section{Isolation and pathogenicity of $\boldsymbol{R}$. solani}

Ten isolates of $R$. solani were selected based on the cultural characteristics. They were marked as BRs105, BRs205, BRs305, BRs405, BRs505, BRs605, BRs705, BRs805, BRs905 and BRs1005. All the isolates were tested for their pathogenicity in BR11. All the tested isolates were found pathogenic and produced typical sheath blight symptom. Out of the ten isolates, the growth of BRs305 was faster and produced bigger sclerotia. The isolate BRs 305 was used as test pathogen throughout the experimental period owing to its nice growth on agar medium.

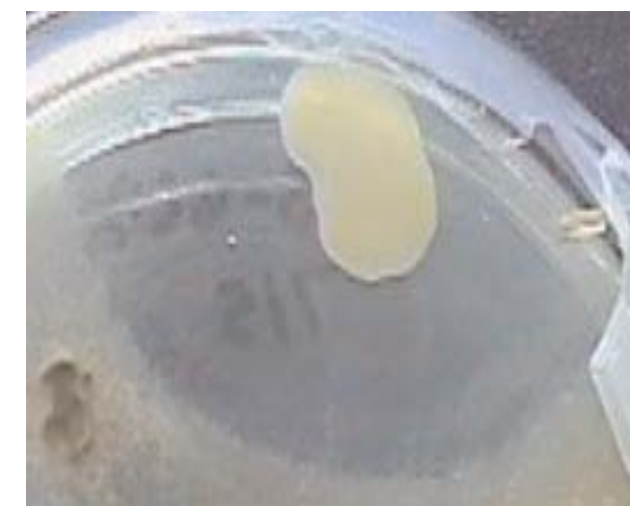

BanShbFPS5(S2)

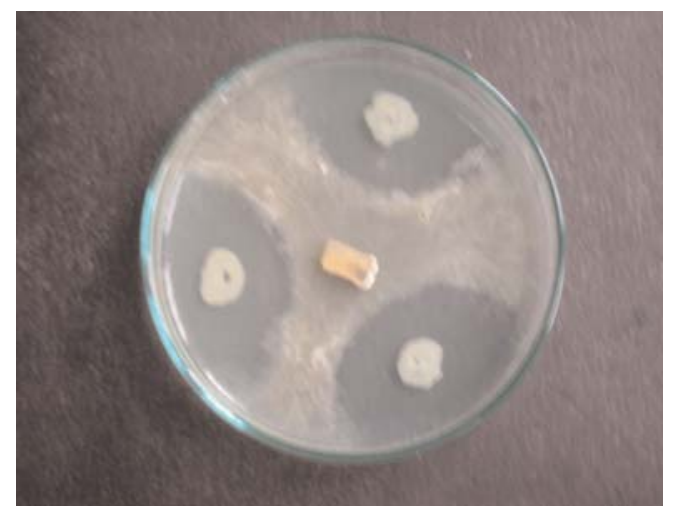

BanShb581(1) (S1)

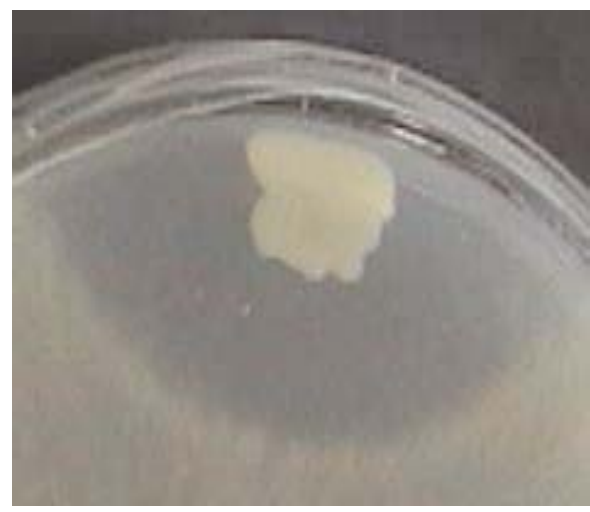

BanShb 738(3)(S3)

Fig. 1. Maximum inhibition zone produced by three antagonistic Bacteria on PDA medium 


\section{Isolation of bacteria}

About 139 plant samples were collected from Rajshahi, Bogra, Comilla and Gazipur during T. Aman season in 2002 and 2005. From the collected samples, fifty isolates of ShB associated bacteria were isolated for antagonism test. Each isolate of bacteria was selected through streaking and restreaking by picking single colony. Each isolate was marked separately. All the bacterial isolates showed more or less antagonistic action to ShB isolate (BRs305).

\section{In vitro screening of sheath blight associated bacteria for antibiosis}

Fifty isolates of antagonistic bacteria were screened for their extent of production of inhibition zone against $R$. solani. The inhibition zones produced by the test antagonistic bacteria were greatly varied. Inhibition zones ranged from 3.89 to $19.94 \mathrm{~mm}$. Eleven isolates produced more than $15 \mathrm{~mm}$ inhibition zone. Finally, three isolates; BanShb 738(3), BanShbFPS5(2)B and BanShb581(1) were selected based on maximum production of inhibition zone. The inhibition zones were 19.94, 18.30 and $16.45 \mathrm{~mm}$, respectively.
In vitro effect of three antagonistic bacterial isolates on growth of $R$. solani

Germination of sclerotia was affected when soaked with bacterial suspension for different intervals. In most of the cases, 12 hrs soaking time performed better results. The sclerotia did not germinate even up to 12 days in $\mathrm{S}_{2}$ (BanShbFPS5(2)) while 2 to 4 days delayed germination of the sclerotia was noticed in $\mathrm{S}_{1}$ (BanShb581(1)) and $\mathrm{S}_{3}$. In addition to its delayed germination, percent germination was also low in isolates $\mathrm{S}_{1}$ and $\mathrm{S}_{2}$ (only 5\% sclerotial germination was noted up to 12 days for $S_{1}$ but it went up to $15 \%$ for $S_{3}$ ).

\section{In vivo antagonistic effect of three bacterial isolates to control ShB of rice in pot}

Like germination, disease initiation was also delayed due to soaking of sclerotia in antagonistic bacterial suspension in different hours (Table I). Disease initiated at least 6 to 9 days later while disease appeared just 1-2 days in control 1 and 2. Variations among the isolates on disease initiation and percent tiller infection were found in the same treatments. Overall, disease initiation delayed 22 to 25 days in the 6 and

Table I. Effect of antagonistic bacteria on the development of sheath blight of rice

\begin{tabular}{|c|c|c|c|c|}
\hline \multirow[t]{2}{*}{ Isolates } & \multirow[t]{2}{*}{ Soaking hours } & \multicolumn{2}{|c|}{$\begin{array}{l}\text { Disease initiation and } \\
\text { percent tiller infection }\end{array}$} & \multirow[t]{2}{*}{$\begin{array}{c}\text { Healthy tiller } \\
\text { (\%) }\end{array}$} \\
\hline & & Disease delayed (days) & Tiller infection (\%) & \\
\hline \multirow[t]{4}{*}{ BanShb581(1)S1 } & 1 & $9-23$ & 58.33 & 41.67 \\
\hline & 3 & $21-24$ & 16.66 & 83.44 \\
\hline & 6 & $22-23$ & 16.66 & 83.44 \\
\hline & 12 & $10-21$ & 25.00 & 75.00 \\
\hline \multirow[t]{4}{*}{ BanShbFPS5(2)S2 } & 1 & $7-23$ & 24.99 & 75.01 \\
\hline & 3 & $10-22$ & 50.00 & 50.00 \\
\hline & 6 & 22 & 8.33 & 91.67 \\
\hline & 12 & $24-25$ & 16.66 & 83.44 \\
\hline \multirow[t]{4}{*}{ BanShb738(3)S3 } & 1 & $8-25$ & 88.89 & 11.11 \\
\hline & 3 & $6-23$ & 77.78 & 22.22 \\
\hline & 6 & 11 & 11.11 & 88.89 \\
\hline & 12 & 22 & 22.22 & 77.78 \\
\hline \multirow[t]{4}{*}{ Control 1 (soaked in water) } & 1 & $2-3$ & 100.00 & 00.00 \\
\hline & 3 & $2-3$ & 100.00 & 00.00 \\
\hline & 6 & $1-5$ & 100.00 & 00.00 \\
\hline & 12 & 1 & 100.00 & 00.00 \\
\hline Control 2 & (non-soaked) & 1 & 100.00 & 00.00 \\
\hline
\end{tabular}


12 hrs soaking in most cases. Although disease appeared early in sometimes (12 h soaking of $\mathrm{S}_{1}$ ), percent tiller infection was lower (less than 25\%) than the both controls. Percent healthy tillers were also higher in different treatments than those of controls. No healthy tillers were found in control treatments. On the other hand, percent healthy tillers were recorded 41.67 to $83.33,50.0$ to 91.67 and 11.11 to 88.89 with $S_{1}, S_{2}$ and $S_{3}$ treated plants respectively. However, when sclerotia soaked with these three isolates for 6 and 12 hours respectively, disease development was drastically reduced than those of other soaking hrs used.

Besides disease initiation, percent tiller infection, percent hill infection and percent relative lesion height was also less due to the effect of different treatments. Variation among the isolates was found in just after inoculation (at maximum tillering stages) and gradually it increased with plant growth. Although \%RLH was lower in boot stage, finally, no variation was found or sometimes it became higher than the controls (Table II).
Analysis of Variance (ANOVA) was used for significance test. Results prevails that for four different soaking hours(1,3,6 and 12 hours), Tiller infection(TI), Hill infection(HI) and Relative lesion height(RLH) percentage varies significantly at $5 \%$ level of significance $(\mathrm{p}<0.05)$ in maximum tillering stage, booting stage and flowering stage, except RLH percentage in maximum tillering stage, booting stage. However, for different antagonistic bacterial insolates TI, HI and RLH percentage in all stage do not vary significantly $(\mathrm{p}<0.05)$ at $5 \%$ level of significance.

\section{In vivo antagonistic effect of seven bacterial isolates to control sheath blight of rice in culture solution}

The results of bacterial isolates to control ShB of rice in culture solution (an artificial media where necessary elements for plant growth were used) are presented in Table II. The ShB disease development reduced tremendously when antagonistic bacteria treated sclerotia were inoculated. None of the antagonistic bacterial isolate treated sclerotia pro-

Table II. In- vivo effect of antagonistic bacteria on percent tiller infection, hill infection and RLH at different crop stages due to soaking of sclerotia in antagonistic bacterial suspension

\begin{tabular}{l|c|ccc|ccc|ccc}
\hline \multirow{2}{*}{ Isolates } & Soaking & \multicolumn{3}{|c|}{ Maximum tillering stage } & \multicolumn{3}{c|}{ Booting stage } & \multicolumn{3}{c}{ Flowering stage } \\
\cline { 2 - 10 } & & TI & HI & RLH & TI & HI & RLH & TI & HI & RLH \\
& & $(\%)$ & $(\%)$ & $(\%)$ & $(\%)$ & $(\%)$ & $(\%)$ & $(\%)$ & $(\%)$ & $(\%)$ \\
\hline BanShb581(1)S1 & 1 & 16.89 & 25.00 & 39.07 & 18.84 & 50.00 & 40.11 & 28.64 & 66.67 & 42.22 \\
& 3 & 0.00 & 0.00 & 0.00 & 2.15 & 16.67 & 27.50 & 31.32 & 58.33 & 40.77 \\
& 6 & 0.00 & 0.00 & 0.00 & 6.01 & 16.67 & 26.25 & 22.64 & 66.67 & 37.06 \\
& 12 & 2.60 & 8.33 & 25.00 & 14.33 & 25.00 & 33.64 & 21.71 & 66.67 & 32.35 \\
BanShbFPS5(2)S2 & 1 & 2.71 & 16.67 & 28.13 & 4.02 & 20.00 & 28.00 & 11.35 & 50.00 & 27.22 \\
& 3 & 4.64 & 16.67 & 46.67 & 26.22 & 50.00 & 38.11 & 28.14 & 75.00 & 48.87 \\
& 6 & 0.00 & 0.00 & 0.00 & 1.11 & 8.33 & 10.00 & 0.52 & 8.33 & 20.00 \\
& 12 & 0.00 & 0.00 & 0.00 & 0.56 & 16.67 & 32.5 & 7.22 & 25.00 & 42.03 \\
BanShb738(3)S3 & 1 & 20.27 & 66.67 & 45.88 & 37.11 & 88.89 & 38.63 & 38.54 & 88.89 & 42.55 \\
& 3 & 35.09 & 66.67 & 34.54 & 37.94 & 77.78 & 43.16 & 37.97 & 100.0 & 43.01 \\
& 6 & 1.31 & 11.11 & 40.00 & 1.71 & 11.11 & 35.00 & 4.48 & 44.44 & 42.5 \\
& 12 & 0.00 & 0.00 & 0.00 & 4.27 & 22.22 & 27.50 & 31.03 & 100.0 & 40.13 \\
Control 1 & 1 & 21.24 & 100.0 & 34.53 & 54.94 & 100.0 & 45.11 & 76.06 & 100.0 & 52.5 \\
& 3 & 45.4 & 100.0 & 22.78 & 66.02 & 100.0 & 43.11 & 61.29 & 100.0 & 60.51 \\
& 6 & 19.24 & 100.0 & 30.00 & 37.72 & 100.0 & 37.65 & 48.00 & 100.0 & 44.77 \\
& 12 & 18.33 & 100.0 & 46.67 & 22.56 & 100.0 & 50.00 & 33.28 & 100.0 & 59.46 \\
Control 2 & Unsoaked & 72.41 & 100.0 & 29.28 & 73.37 & 100.0 & 45.88 & 73.37 & 100.0 & 37.72 \\
\hline
\end{tabular}

$\mathrm{TI}=$ Tiller infection, $\mathrm{HI}=$ Hill infection, $\mathrm{RLH}=$ Relative lesion height 
duced disease up to one week except BanShbFPS5 (2)B (13\%) and BanShb728 (2) 8.3\%. The isolate BanShb738 (3) treated sclerotia produced lowest disease (4.76\%) even at 28 DAI than that of control which was followed by BanShb581(1) (9\%) and BanShbFPS6 (1) 11.12\%. The disease development was maximum, (40\%) in the 4th week after inoculation when the sclerotia were not treated with antagonistic bacteria. However, three isolates of antagonistic bacteria i.e. BanShb738(3), BanShB581(1) and BanShBFPS6 (1) were found most effective to control sheath blight disease. These isolates, BanShb738 (3), BanShb581 (1) and BanShbFPS6 (1) reduced sheath blight disease development, 35.24, 31.0 and $28.9 \%$ respectively compare to control (60\%).

\section{Effect of seedlings soaked with an antagonistic bacterial suspension to control ShB}

The results did not show any significant differences $(\mathrm{p}=0.66>0.05)$ among the different soaking hrs. of seedlings with antagonistic bacteria in \% tiller infection (TI), \% hill infection (HI), \% relative lesion height (RLH) and \% severity index (SI) either in boot or maturity stage although some variations were noticed. Percent tiller infections were less (18.6\% and $21.4 \%$ ) when seedlings were soaked for six hours in both the stages respectively compared to control. On the other hand, percent RLH was less with 3 and $1 \mathrm{hr}$ soakings (18.11 and $15.12 \%$ ) at boot stage but the lowest \% RLH was recorded in control followed by one hr. soaking. At boot stage, the lowest percent hill infection (83\%) was observed in six hrs soaking seedlings but the remaining soaking hrs had no effect where $100 \%$ hill infections were recorded but at maturity stage, it was completely different, where 12 hrs soaking seedlings showed the lowest (75\%) hill infection followed by $3 \mathrm{hr}$. soakings (87.5\%). Severity index was found lower in all the treatments compared to control at boot stage. However, it was found less (2.92\%) in 6 hrs soaking seedlings at maturing stage.

\section{Effect of seedlings and sclerotia soaked with antagonistic bacteria to control ShB}

The experiment was conducted to see the effect of 10 antagonistic bacterial isolates by using seedlings and sclerotia soaking to control sheath blight disease in pot. ShB disease incidences were recorded up to 21 days after inoculation (DAI). No disease symptom was noticed up to one week in seedlings soaked with antagonistic bacteria except in the inoculated control pot where $10 \%$ infection was recorded.
But disease development was progressed (0 - 30\%) in subsequent weeks in almost all the antagonistic bacteria soaked seedlings except the isolates, BanShbFPS5(2)B and BanShb728(2). No disease symptom appeared up to 21 DAI when seedlings and sclerotia were soaked simultaneously with BanShbFPS5 (2)B and BanShb728(2) However, ShB disease incidence drastically reduced $(100 \%$ - 38\%) when seedlings and sclerotia both were soaked with all the bacterial isolates except BanShb725(1) and BanShb726(4).

\section{Conclusion}

The results of the study suggested that the fluorescent and non-fluorescent bacteria detected from ShB infected plants were capable of suppressing the growth of $R$. solani in vitro by inhibiting mycelial growth and sclerotial germination. The inhibition zones produced by the test isolates of antagonistic bacteria greatly varied. From this result, it could be said that biological control might be effective and alternative in minimizing the incidence of the disease. Hundred percent control of ShB was observed when seedlings soaked with the test bacteria followed by sclerotia soaking with the same bacteria. Soaking of both the seedlings and sclerotia with the test bacteria was found most effective to control ShB than soaking of seedlings alone with bacterial suspension at different hr. However, the data from the in vitro and in vivo experiments showed that selected strains of antagonistic bacteria used in this study, such as, BanShbFPS5(2)B, BanShb738(3), BanShbFPS6(1) and BanShb728(2) reduced pathogenic activities of $R$. solani. Biological protection against infection is accomplished by destroying the existing inocula, by preventing the formation of additional inocula, or by weakening and displacing the existing virulent pathogen population. This is achieved through protection of plant material and roots with biological seed treatments, or suppression of pathogen by the introduction of plant associated antagonists into the rhizosphere. Therefore, it could be concluded that presently tested antagonistic bacteria could control sheath blight disease development and it could also delay the epidemics of the disease.

\section{References}

Akter S., Sharma N. R., Rahman M. M. and Ali A. (2003) Pathogen isolation, pathogenicity and interaction of Rhizoctonia spp. Paper accepted to publish in the proceeding of stake holder workshop held on December 3, 2003. Organized by Rice Sheath Blight Disease 
Complex Project. pp. 8-10.

BBS (2004) Statistical Pocket Book of Bangladesh. Ministry of planning, Government of Peoples' Republic of Bangladesh. pp. 187.

Hossain M. and Mia M. A. T.(2001) Management of sheath blight disease of rice under farmer's field condition. Bang. J. Plant Path. 17(1/2):13-16.

Islam Z. R., Pamplona A. D., Atkinson and Azucena E. J. (2003) Biological control of rice disease. IRRI Rice Knowledge Bank. pp.24.

Miah S. A., Shahjahan A. K. M., Hossain M. A. and Sharma, N. R.(1985) Survey of rice diseases in Bangladesh. Tropical Pest Management, 31(3): 208-213.
Miah S. A. and Shahjahan A. K. M.(1987) Mathe Dhaner Rog Nirnoy Tar Pratikar (In Bangla, Rice disease identification and their control in the field). Bangladesh Rice Research Institute, Gazipur, Bangladesh. pp. 60.

Naidu V. D. (1989) Influence of sheath blight of rice on grain and straw yield in some popular local varieties. Journal of Research, Assam Agricultural University. 10(1-2): 78-80.

Ou S. H. (1985) Rice Diseases. Commonwealth Mycological Institute, Kew, England. pp. 380

Shahjahan A. K. M. and Mew T. W .(1986) Sheath spot of rice in the Philippines. Intl. Rice Res. 11(3): 17.

Received : June 18, 2009;

Accepted : January 06, 2010 